\title{
KAJIAN FISIOLOGIS LOBSTER AIR TAWAR (Cherax quadricarinatus) PADA SUHU DINGIN SEBAGAI DASAR UNTUK PENANGANAN DAN TRANSPORTASI HIDUP SISTEM KERING
}

\author{
Diah Ikasari*), Syamdidi*), dan Theresia Dwi Suryaningrum)
}

\begin{abstract}
ABSTRAK
Kajian terhadap sifat fisiologis lobster air tawar (Cherax quadricarinatus) pada suhu dingin telah dilakukan. Kajian ini bertujuan untuk menentukan metode dan waktu shock sebagai dasar untuk penanganan dan transportasi lobster hidup sistem kering. Penelitian dilakukan dengan menempatkan lobster pada media air yang bersuhu $12^{\circ} \mathrm{C}$ (shock secara langsung) dan pada media air yang suhunya diturunkan secara bertahap (shock secara bertahap) dari suhu lingkungan $\left(28-29^{\circ} \mathrm{C}\right)$ hingga $12^{\circ} \mathrm{C}$ selama 30 menit. Pengamatan dilakukan setiap 15 menit selama 60 menit terhadap aktivitas dan metabolisme, dengan mengukur nilai respirasi dan produksi metabolit lobster. Hasil penelitian menunjukkan bahwa dengan metode shock secara langsung, aktivitas dan metabolisme lobster air tawar terendah terjadi pada menit ke-45 dengan tingkat respirasi $81,2 \mathrm{ppm} \mathrm{O} / \mathrm{kg}$ ikan/jam, produksi $\mathrm{NH}_{3}$ sebesar $1,29 \mathrm{ppm} / \mathrm{kg}$ ikan/jam, dan $\mathrm{NO}_{2}$ sebesar 0,036 $\mathrm{ppm} / \mathrm{kg}$ ikan/jam. Adapun dengan metode shock secara bertahap, aktivitas dan metabolisme

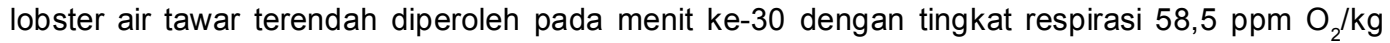
ikan/jam, produksi $\mathrm{NH}_{3}$ sebesar $0,76 \mathrm{ppm} / \mathrm{kg}$ ikan/jam, dan $\mathrm{NO}_{2}$ sebesar $0,092 \mathrm{ppm} / \mathrm{kg}$ ikan/jam. Metode shock secara langsung selama 45 menit dan metode shock secara bertahap selama 30 menit berpeluang untuk digunakan dalam penanganan dan transportasi lobster air tawar hidup.
\end{abstract}

\section{ABSTRACT: Study on the physiological characteristics of freshwater lobster (Cherax quadricarinatus) at low temperature as a basic of live handling and transportation with dry system. By: Diah Ikasari, Syamdidi, and Theresia Dwi Suryaningrum}

\begin{abstract}
Study on the physiological characteristics of freshwater lobster (Cherax quadricarinatus) at low temperature was carried out. The aim of this study was to find out shocking method and time that can be used for handling and transport of live lobster with dry system. Live freshwater lobsters were subjected to direct cold shock by putting them in chilled water at $12^{\circ} \mathrm{C}$, and by gradual cold shock by putting them in freshwater whereby the temperature was gradually decreased from $28-29^{\circ} \mathrm{C}$ to $12^{\circ} \mathrm{C}$ for 30 minutes. Observation on lobsters activities and metabolism were carried out every 15 minutes for 60 minutes, by measuring the rates of respiration and metabolite production. Results showed that direct cold shock gave the lowest activities and metabolism after

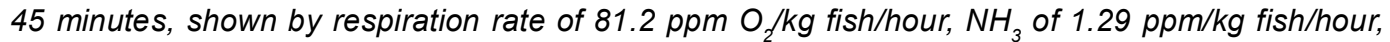
and $\mathrm{NO}_{2}$ of $0.036 \mathrm{ppm} / \mathrm{kg}$ fish/hour. Meanwhile gradual cold shock gave the lowest activities and metabolism after 30 minutes, shown by respiration rate of $58.5 \mathrm{ppm} / \mathrm{kg}$ fish/hour, $\mathrm{NH}_{3}$ of $0.76 \mathrm{ppm} /$ $\mathrm{kg}$ fish/hour, and $\mathrm{NO}_{2}$ of $0.092 \mathrm{ppm} / \mathrm{kg}$ fish/hour. Direct cold shock for 45 minutes and gradual cold shock for 30 minutes were potential to be used for handling and transport of live freshwater lobsters.
\end{abstract}

KEYWORDS: freshwater lobster, activity and metabolism, direct cold shock and gradual cold shock

\section{PENDAHULUAN}

Permintaan komoditas ikan hidup, terutama untuk ikan yang mempunyai nilai ekonomis tinggi semakin meningkat dengan pesat baik di pasar domestik maupun di pasar internasional. Ikan dalam bentuk hidup diyakini lebih sehat dan terhindar dari bahan pengawet, seperti penggunaan formalin yang saat ini sedang marak terjadi pada produk-produk hasil perikanan. Salah satu komoditas perikanan hidup di perairan tawar yang memiliki nilai ekonomis tinggi adalah lobster air tawar jenis Cherax quadricarinatus. Permintaan lobster air tawar untuk pasar ekspor dalam keadaan hidup sangat tinggi terutama untuk negaranegara Eropa dan Asia seperti Jepang, Korea,Taiwan, China, dan Singapura (Lawrence, 1995). Di Australia, lobster hidup jenis Cherax quadricarinatus biasa dijual dengan harga 11.50\$AUS/kg untuk ukuran 30-50 g hingga 19.00\$AUS/kg untuk ukuran lebih dari $120 \mathrm{~g}$ (Jones, 1998). Permintaan di dalam negeri juga semakin meningkat khususnya di beberapa kota besar seperti Jakarta, Yogyakarta, dan Serang. Di

\footnotetext{
Peneliti pada Balai Besar Riset Pengolahan Produk dan Bioteknologi Kelautan dan Perikanan, DKP
} 
Yogyakarta misalnya, lobster ukuran konsumsi dipasarkan untuk memenuhi permintaan restoran yang berkisar $1,5 \mathrm{~kg} / \mathrm{ming} g u$ dengan harga jual Rp. 150.000 - Rp. 200.000/kg (Wibowo et al., 2005).

Peluang pasar yang cukup menjanjikan tersebut perlu mendapat dukungan berupa teknologi penanganan transportasi ikan hidup yang ekonomis, efektif, dan efisien. Untuk transportasi lobster air tawar hidup jarak jauh, terutama untuk ekspor, penggunaan transportasi sistem kering dipandang merupakan cara yang efisien. Pada transportasi sistem kering, lobster dikondisikan dalam keadaan metabolisme rendah agar daya tahan di luar habitatnya tinggi. Untuk itu sebelum ditransportasikan, lobster diimotilisasi terlebih dahulu. Imotilisasi dapat dilakukan salah satunya dengan menggunakan shock suhu rendah (Wibowo et al., 1994a).

Dari penelitian sebelumnya, telah diperoleh titik suhu kritis bagi lobster yang berpeluang untuk diterapkan dalam transportasi, yaitu $12^{\circ} \mathrm{C}$ (Wibowo et al., 2005). Namun demikian, suhu kritis tersebut perlu dikaji lebih lanjut untuk dapat digunakan sebagai dasar transportasi lobster dengan sistem kering. Penggunaan metode shock dan waktu shock yang berbeda dapat berpengaruh terhadap aktivitas dan metabolisme lobster air tawar. Menurut Surono et al. (1993), proses pemingsanan dengan shock secara bertahap menimbulkan stres pada ikan dan memerlukan waktu yang lebih panjang hingga pingsan bila dibandingkan dengan menggunakan metode shock secara langsung. Penelitian ini bertujuan untuk mengkaji sifat fisiologis lobster air tawar jenis Cherax quadricarinatus pada suhu rendah dalam selang waktu tertentu dengan metode shock yang berbeda. Data yang diperoleh diharapkan dapat digunakan sebagai dasar untuk menentukan metode shock dan waktu shock yang paling efektif dan efisien untuk transportasi lobster air tawar hidup sistem kering.

\section{BAHAN DAN METODE}

\section{Bahan}

Bahan utama yang digunakan dalam penelitian ini adalah lobster air tawar jenis Cherax quadricarinatus dalam keadaan hidup yang diperoleh dari daerah Yogyakarta. Lobster yang digunakan memiliki bobot \pm 30 gram/ekor, panjang total $16-22 \mathrm{~cm}$, panjang karapas 9-14 cm serta lebar 1,9-2,6 cm. Lobster dipilih yang memiliki anggota tubuh lengkap, tidak moulting, dan bugar.

Bahan bantu lain yang digunakan dalam penelitian ini adalah es untuk mendinginkan media air, reagent test kit untuk analisis mutu air (Hach Colorimeter), akuades dan akuabides.
Peralatan yang digunakan dalam penelitian ini berupa respirometer yang terbuat dari akuarium $60 \mathrm{x}$ $60 \times 40 \mathrm{~cm}$ bertutup kerucut yang dilengkapi dengan aerator, sirkulator, termometer (Kane May KM 1242, Thermoline), DO meter (YSI model 58), serta diberi outlet dan inlet untuk keluar masuknya air. Sedangkan alat bantu lainnya berupa timbangan (Lion Star $2 \mathrm{~kg}$ ), pencatat waktu (timer), dan test kit untuk analisis mutu air (Hach Colorimeter).

\section{Metode}

Lobster terlebih dahulu ditimbang sebelum diberi shock suhu rendah. Lobster yang digunakan untuk percobaan adalah \pm 600 gram atau 20 ekor ( $30 \mathrm{gram} /$ ekor). Pada metode shock secara langsung, lobster dimasukkan ke dalam respirometer yang berisi media air penuh bersuhu $12^{\circ} \mathrm{C}$. Adapun pada metode shock secara bertahap dilakukan dengan memasukkan lobster ke dalam respirometer yang berisi media air suhu lingkungan $\left(28-29^{\circ} \mathrm{C}\right)$ yang kemudian diturunkan secara bertahap dengan mengalirkan air dingin $\left(0-1^{\circ} \mathrm{C}\right)$ selama 30 menit sampai suhunya mencapai $12^{\circ} \mathrm{C}$ (Suryaningrum et al., 2006). Setelah suhu mencapai $12^{\circ} \mathrm{C}$, dilakukan pengamatan respirasi dengan cara mematikan aerator dan sirkulator, kemudian gelembunggelembung udara yang menempel di dinding respirometer dibersihkan, dan respirometer ditutup rapat. Kondisi ini dipertahankan selama 5 menit kemudian sampel air diambil pada menit ke-0 dan menit ke-5. Parameter pengamatan adalah oksigen terlarut, metabolit $\mathrm{NH}_{3}$, dan $\mathrm{NO}_{2}$.

Setelah pengamatan selesai dilakukan, respirometer dibuka, aerator dan sirkulator dihidupkan kembali. Pengamatan ini dilakukan setiap 15 menit selama 60 menit. Suhu media air selama 60 menit shock dipertahankan agar tetap dalam kisaran $12^{\circ} \mathrm{C}$ dengan memasukkan dan mengeluarkan air melalui inlet dan outlet yang terdapat pada respirometer.

Selain pengamatan metabolisme yang mencakup respirasi (konsumsi oksigen), metabolit $\mathrm{NH}_{3}$ dan $\mathrm{NO}_{2}$, juga dilakukan pengamatan terhadap aktivitas lobster meliputi gerakan lobster dalam media air serta respon terhadap rangsangan sentuhan yang diberikan. Percobaan dilakukan dengan dua kali ulangan.

Laju respirasi (konsumsi oksigen) lobster dihitung dari tingkat penurunan kandungan oksigen terlarut pada awal pengamatan (menit ke-0) dan akhir pengamatan (menit ke-5) dibagi dengan bobot lobster $(\mathrm{kg})$ per satuan waktu (jam). Produksi metabolit dihitung berdasarkan peningkatan kandungan metabolit pada awal pengamatan (menit ke-0) dan akhir pengamatan (menit ke-5) dibagi dengan bobot lobster $(\mathrm{kg})$ per satuan waktu (jam) (Wibowo et 
al., 2002; Syamdidi et al., 2006). Diagram alir metode shock secara langsung dan bertahap dapat dilihat pada Gambar 1.

\section{HASIL DAN BAHASAN}

\section{Aktivitas Lobster Air Tawar}

Aktivitas lobster air tawar pada suhu $12^{\circ} \mathrm{C}$ dengan metode shock langsung dapat dilihat pada Tabel 1.
Pada saat lobster air tawar dimasukkan ke dalam media air dengan suhu $12^{\circ} \mathrm{C}$ secara langsung, perubahan suhu air normal ke suhu dingin secara drastis membuat lobster panik sehingga lobster langsung meloncat-loncat ke belakang secara tidak beraturan. Namun perubahan suhu media tersebut dengan cepat diadaptasi oleh lobster. Gerakangerakan panik tersebut hanya berlangsung 1-3 menit pada 15 menit awal shock, kemudian lobster tenang kembali. Hal ini sesuai dengan penelitian

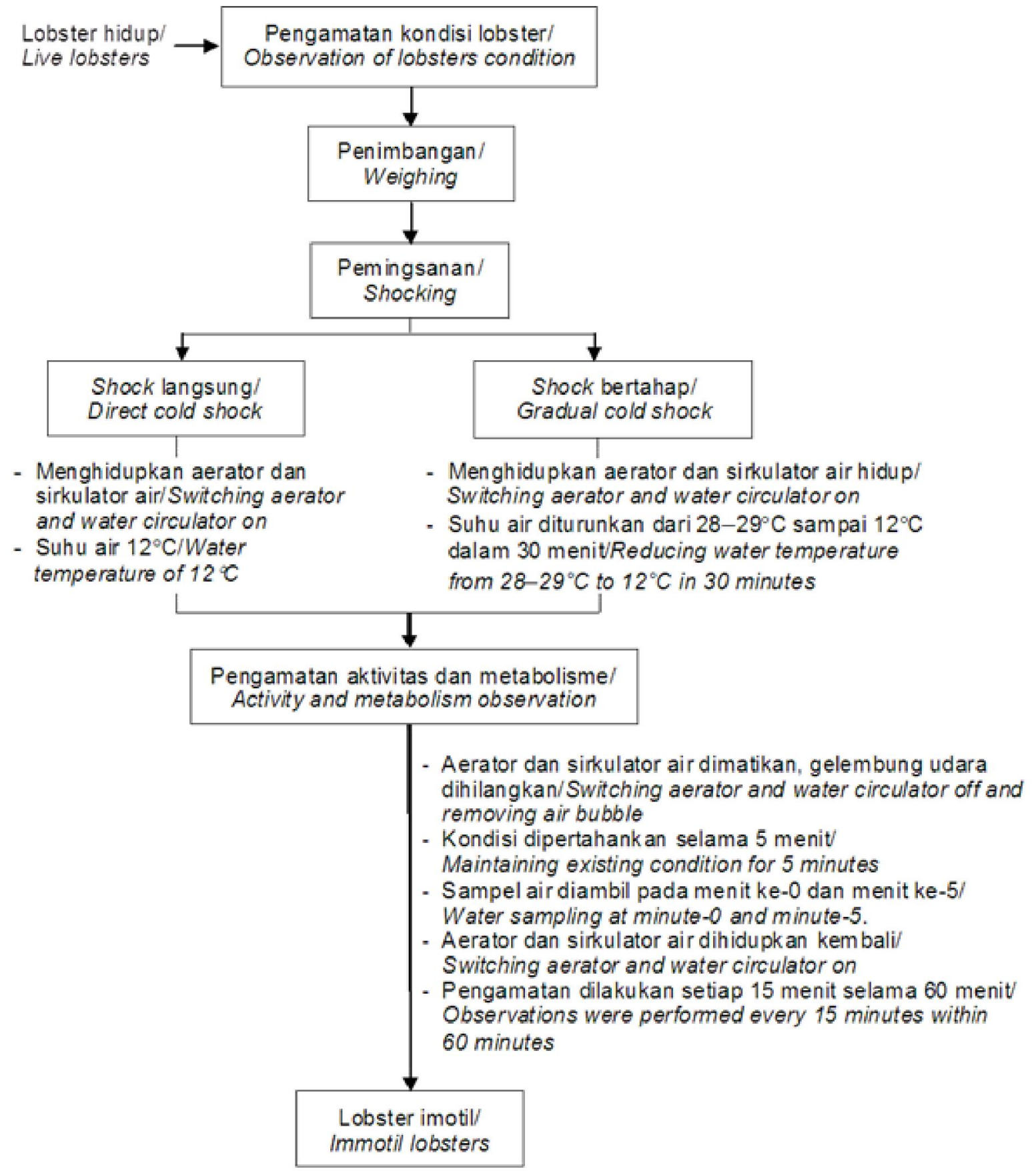

Gambar 1. Diagram alir metode shock secara langsung dan bertahap.

Figure 1. Flow chart of direct and gradual cold shock methods. 
Tabel 1. Respon aktivitas lobster air tawar pada saat shock langsung pada suhu $12^{\circ} \mathrm{C}$ Table 1. Freshwater lobster activity responding to direct cold shock treatment at $12^{\circ} \mathrm{C}$

\begin{tabular}{|c|c|c|}
\hline No & $\begin{array}{l}\text { Waktu (menit)l } \\
\text { Time (minutes) }\end{array}$ & Aktivitas lobster/Lobster activity \\
\hline \multirow[t]{2}{*}{1} & 0 & $\begin{array}{l}\text { Ketika lobster dimasukkan ke dalam media air, sebagian lobster langsung } \\
\text { menyentak-nyentak kemudian jatuh dengan posisi tubuh miring. Lobster tidak } \\
\text { bergerak, respon lemah, dan sebagian lobster limbung/ }\end{array}$ \\
\hline & & $\begin{array}{l}\text { When lobsters were put into medium, they moved with uncontroled movement, } \\
\text { and then fell down to the bottom. No movement can be observed, lobsters } \\
\text { response were weak and mostly lost their balance. }\end{array}$ \\
\hline \multirow[t]{2}{*}{2} & 15 & $\begin{array}{l}\text { Lobster tenang, tidak banyak bergerak, kaki jalan dan kaki renang bergerak } \\
\text { perlahan, respon terhadap rangsangan melemah, keseimbangan mulai } \\
\text { terganggu/ }\end{array}$ \\
\hline & & $\begin{array}{l}\text { Lobsters were calm, the walking and swimming legs moved slowy, response } \\
\text { to stimulation was weak and started to loose their balance. }\end{array}$ \\
\hline \multirow[t]{2}{*}{3} & 30 & $\begin{array}{l}\text { Lobster tenang, kaki jalan dan kaki renang kaku, keseimbangan hilang, ketika } \\
\text { disentuh respon lemah/ }\end{array}$ \\
\hline & & $\begin{array}{l}\text { Lobsters were calm, the walking and swimming legs becoming stiff, lost their } \\
\text { balance, no response on physical stimulation. }\end{array}$ \\
\hline \multirow[t]{2}{*}{4} & 45 & $\begin{array}{l}\text { Lobster tenang, sebagian lobster memiliki posisi tubuh miring, kaki jalan dan } \\
\text { kaki renang kaku, ketika disentuh diam, keseimbangan hilang dan ketika } \\
\text { diangkat tubuh melayang-layang/ }\end{array}$ \\
\hline & & $\begin{array}{l}\text { Lobsters were calm, some of them have abnormal position, the walking and } \\
\text { swimming legs becoming stiff, no response on physical stimulation and lost } \\
\text { their balance. }\end{array}$ \\
\hline \multirow[t]{2}{*}{5} & 60 & $\begin{array}{l}\text { Lobster diam, kaki jalan dan kaki renang diam tidak bergerak, ketika diangkat } \\
\text { lobster diam, keseimbangan tidak ada/ }\end{array}$ \\
\hline & & $\begin{array}{l}\text { Lobsters were calm, no movement can be observed, no response when they } \\
\text { were taken out from water. Lobsters lost their balance. }\end{array}$ \\
\hline
\end{tabular}

Suryaningrum et al. (1994) pada lobster hijau pasir (Panulirus humarus) yang diberikan shock secara langsung pada suhu $12^{\circ} \mathrm{C}$ selama 15 menit, menunjukkan adanya gerakan-gerakan panik pada menit ke-0 hingga menit ke-3.

Setelah 45 menit di dalam media, lobster mulai kehilangan keseimbangannya. Hal ini dibuktikan bahwa ketika disentuh lobster diam dan ketika diangkat, tubuh melayang-layang. Pada menit ke-60, lobster mengalami disorientasi, keseimbangan tidak ada, dan kaki-kaki jalannya diam tak bergerak. Hal ini sesuai dengan hasil penelitian Wibowo et al. (2002) mengenai kajian sifat fisiologis ikan kerapu pada suhu rendah. Setelah mengalami kepanikan, selanjutnya ikan kehilangan keseimbangan dan terjadi disorientasi sehingga ikan roboh.

Aktivitas lobster air tawar pada suhu $12^{\circ} \mathrm{C}$ dengan metode shock secara bertahap dapat dilihat pada Tabel 2. Pada penurunan suhu secara bertahap gerakan lobster yang semula aktif pada suhu normal secara perlahan-lahan menjadi tenang seiring dengan penurunan suhu yang diberikan. Tidak tampak adanya fase panik yang biasa ditunjukkan dengan gerakan meloncat-loncat ke belakang secara tidak beraturan. Kondisi yang sama juga ditunjukkan pada lobster hijau pasir (Panulirus humarus) yang diberikan shock secara bertahap pada suhu $12^{\circ} \mathrm{C}$, yaitu adanya penurunan fase gerakan dari gerakan yang aktif menjadi lebih tenang, tanpa disertai dengan adanya gerakan panik (Wibowo et al., 1994b). Proses aklimatisasi yang berbeda dari kedua metode shock yang digunakan pada dasarnya juga dipengaruhi oleh bobot dan ukuran lobster yang digunakan. Semakin besar bobot dan ukuran lobster yang digunakan maka semakin besar nilai toleransi terhadap suhu dingin yang diberikan. Namun dalam hal ini, berat dan ukuran lobster yang digunakan relatif seragam, yaitu antara \pm 30 gram dengan panjang total $16-22 \mathrm{~cm}$.

Selanjutnya lobster mulai kehilangan keseimbangannya pada menit ke-30, lobster limbung, 
Tabel 2. Respon aktivitas lobster pada saat shock bertahap pada suhu $12^{\circ} \mathrm{C}$

Table 2. Freshwater lobster activity responding to gradual cold shock at $12^{\circ} \mathrm{C}$

\begin{tabular}{|c|c|c|}
\hline No & $\begin{array}{l}\text { Waktu (menit)/ } \\
\text { Time (minutes) }\end{array}$ & Aktivitas lobster/Lobster activity \\
\hline 1 & 0 & $\begin{array}{l}\text { Lobster tenang, tubuh tegak, ekor menekuk, kaki jalan, dan kaki renang } \\
\text { diam tidak bergerak/ } \\
\text { Lobsters were calm, no movement can be found, but sill in normal } \\
\text { position. }\end{array}$ \\
\hline 2 & 15 & $\begin{array}{l}\text { Lobster tenang, posisi tubuh tegak sebagian lobster mulai hilang } \\
\text { keseimbangan, ketika disentuh respon masih ada/ } \\
\text { Lobsters were calm, had a normal position, most of them lost their } \\
\text { balance but still responsive to physical stimulation. }\end{array}$ \\
\hline 3 & 30 & $\begin{array}{l}\text { Lobster limbung, ketika disentuh respon melemah, dan jatuh tergeletak } \\
\text { dengan posisi tubuh miring/ } \\
\text { Lobsters were lost their balance, response to physical stimulation } \\
\text { becoming weak and having abnormal position. }\end{array}$ \\
\hline 4 & 45 & $\begin{array}{l}\text { Lobster diam, kaki jalan dan kaki renang kaku, sebagian tergeletak } \\
\text { dengan posisi tubuh miring, keseimbangan hilang/ } \\
\text { Lobsters were calm, the walking and swimming legs becoming stiff, most } \\
\text { of them laid down on the bottom, lost their balance. }\end{array}$ \\
\hline 5 & 60 & $\begin{array}{l}\text { Lobster tergeletak, diam, kaki jalan dan kaki renang kaku. Ketika diangkat } \\
\text { tubuh lobster melayang-layang/ } \\
\text { Lobsters laid down on the bottom, the walking and swimming legs was } \\
\text { stiff. Lobsters were lost their balance when they were taken out from the } \\
\text { water. }\end{array}$ \\
\hline
\end{tabular}

respon melemah dan posisi tubuh mulai miring. Lobster mengalami disorientasi pada menit ke-45, ditunjukkan dengan kaki jalan dan kaki renang yang mulai kaku dan sebagian lobster jatuh tergeletak di dasar media. Pada menit ke-60 lobster menunjukkan tanda-tanda pingsan, lobster tergeletak di dasar media, kaki jalan dan kaki renang kaku, dan ketika diangkat tubuh lobster melayang-layang.

Pada masing-masing metode shock yang dilakukan, ketika lobster diangkat dari media shock di akhir percobaan, lobster diam, kaki jalan dan kaki renangnya diam kaku, namun tidak menunjukkan adanya mortalitas sewaktu dibugarkan kembali. Hal ini nantinya akan memudahkan dalam penanganan lobster pada saat pengemasan.

\section{Metabolisme Lobster Air Tawar}

\section{Respirasi}

Pengaruh penurunan suhu dengan metode shock secara langsung dan bertahap terhadap respirasi yang dihitung berdasarkan oksigen yang dikonsumsi disajikan pada Gambar 2. Pada shock secara langsung laju respirasi lobster air tawar menunjukkan pola yang cenderung mengalami penurunan hingga 45 menit waktu shock, setelah itu meningkat tajam hingga menit ke-60. Konsumsi oksigen terendah terjadi pada menit ke-45 yaitu sebesar $81,2 \mathrm{ppm} \mathrm{O} /$ $\mathrm{kg}$ ikan/jam. Sedangkan setelah menit ke-45 laju respirasi kembali meningkat. Hal ini menunjukkan bahwa metode shock secara langsung mampu menekan respirasi lobster air tawar. Penurunan laju respirasi ini berhubungan dengan aktivitas lobster selama shock. Lobster mengalami penurunan aktivitas menjadi lebih tenang dan respon yang lemah hingga 45 menit waktu shock. Setelah menit ke-45 lobster menunjukkan tanda-tanda disorientasi dan tidak ada pergerakan, namun konsumsi oksigen justru menunjukkan adanya peningkatan. Hal ini disebabkan karena mulai terjadinya proses aklimatisasi pada lobster, sehingga diperkirakan laju respirasi akan terus meningkat pada menit-menit selanjutnya. Dengan demikian, waktu shock 45 menit dengan metode shock secara langsung berpeluang untuk digunakan dalam penanganan dan transportasi hidup sistem kering. Tingkat konsumsi oksigen yang relatif rendah sesuai dengan kondisi saat transportasi, mengingat jumlah oksigen yang tersedia dalam kemasan sangat terbatas. Namun demikian, lobster air tawar memiliki ambang batas konsentrasi oksigen yang lebih tinggi 


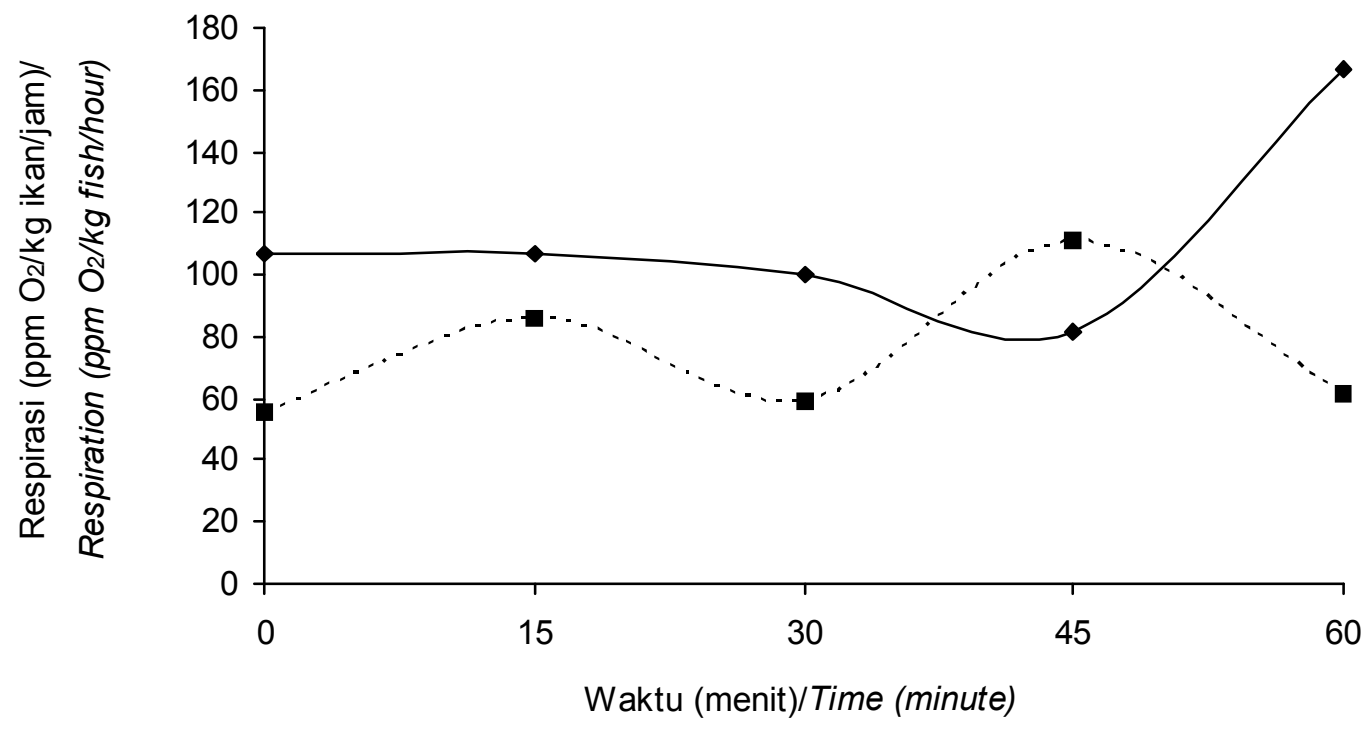

•Shock langsung/Direct cold shock - - - - Shock bertahap/Gradual cold shock

Gambar 2. Laju respirasi lobster air tawar pada suhu $12^{\circ} \mathrm{C}$ selama 60 menit.

Figure 2. Respiration rates of freshwater lobster at $12^{\circ} \mathrm{C}$ within 60 minutes.

bila dibandingkan dengan ikan-ikan yang lain (Lin et al., 1994).

Pada metode shock secara bertahap tingkat konsumsi oksigen lebih rendah bila dibandingkan dengan konsumsi oksigen pada shock secara langsung. Hal ini menunjukkan bahwa lobster yang di-shock dengan menggunakan metode shock secara bertahap memiliki aktivitas yang lebih tenang bila dibandingkan dengan lobster yang di-shock menggunakan metode shock secara langsung. Pada shock secara bertahap tidak tampak adanya fase panik yang ditunjukkan dengan gerakan meloncatloncat ke belakang seperti halnya pada shock secara langsung. Kondisi lobster yang panik akibat proses aklimatisasi terhadap lingkungan baru memerlukan energi lebih banyak. Salah satu sumber energi yang digunakan adalah oksigen (Winarno, 2003). Menurut Berka (1986) apabila ikan berada dalam keadaan panik, maka akan mengkonsumsi oksigen mendekati batas maksimum.

Namun demikian metode shock secara bertahap dapat menimbulkan stres pada ikan bila dibandingkan dengan menggunakan metode shock secara langsung (Surono et al., 1993). Hal ini terlihat pada pola respirasi lobster air tawar yang cenderung berfluktuasi. Konsumsi oksigen meningkat pada 15 menit pertama shock dilakukan, mengalami penurunan pada menit ke-30, meningkat lagi pada menit ke-45, dan turun kembali pada menit ke-60. Konsumsi oksigen terendah diperoleh pada menit ke-30 yaitu sebesar 58,5 ppm O/ $/ \mathrm{kg}$ ikan/jam. Dengan demikian, waktu shock selama 30 menit dengan menggunakan metode shock secara bertahap berpeluang untuk digunakan dalam penanganan dan transportasi lobster air tawar hidup sistem kering. Waktu shock selama 45 menit dengan metode shock secara bertahap sangat berisiko bila digunakan dalam penanganan dan transportasi lobster air tawar hidup sistem kering karena laju respirasi yang meningkat meskipun lobster menunjukkan gerakan yang semakin melemah. Sedangkan waktu shock selama 60 menit kurang efektif meskipun menunjukkan penurunan tingkat konsumsi oksigen karena membutuhkan waktu yang relatif lebih lama.

\section{Produksi Amonia $\left(\mathrm{NH}_{3}\right)$}

Pola produksi amonia lobster air tawar dengan menggunakan metode shock secara langsung dan bertahap disajikan pada Gambar 3. Pada shock secara langsung, produksi amonia meningkat pada 15 menit pertama kemudian mengalami penurunan hingga menit ke-45. Nilai produksi amonia terendah terjadi pada menit ke-45, yaitu sebesar 1,29 ppm/kg ikan/ jam. Laju respirasi dan laju produksi amonia memiliki korelasi dengan aktivitas lobster selama shock. Pada 15 menit pertama shock lobster menunjukkan gerakan panik sehingga respirasi meningkat. Hal ini membuat kandungan oksigen dalam media menjadi terbatas akibat tingkat konsumsi yang tinggi secara terus menerus. Akibatnya, lobster berada dalam kondisi stres yang dapat meningkatkan produksi amonia dari dalam tubuh. Setelah 15 menit shock laju produksi 


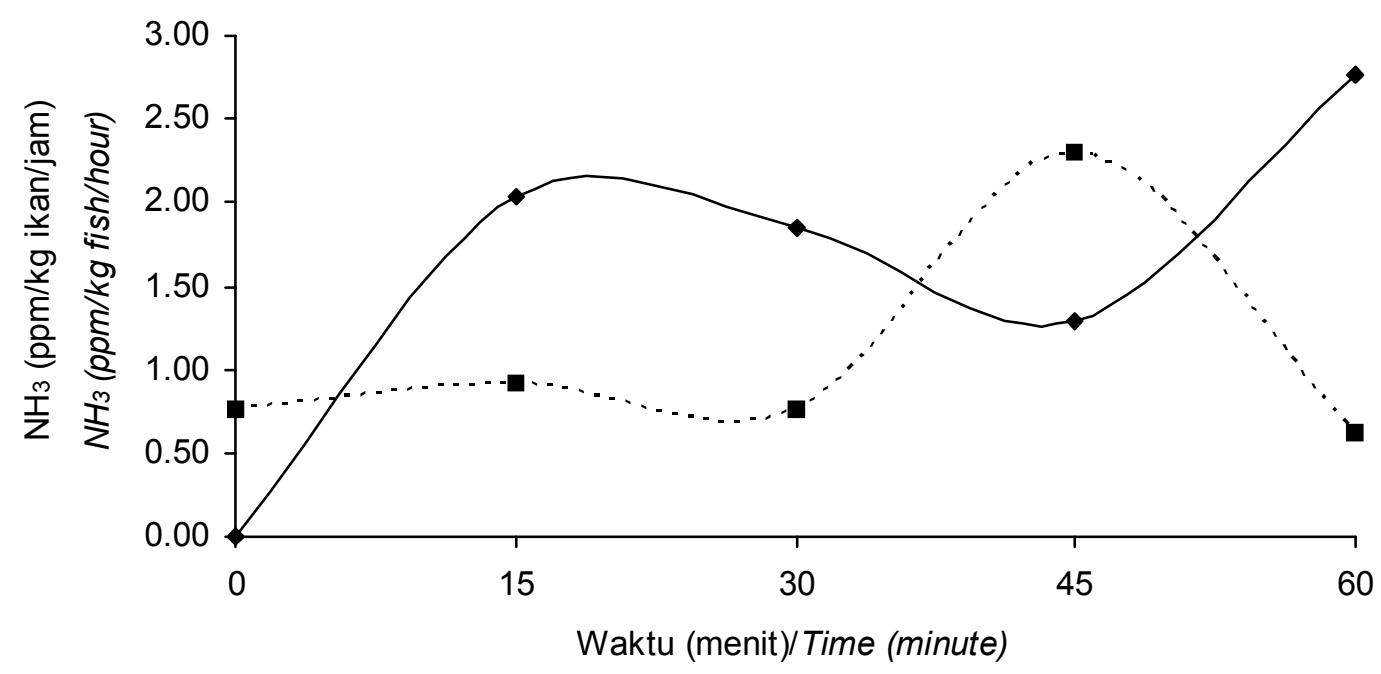

$\longrightarrow$ Shock langsung/Direct cold shock - - - - Shock bertahap/Gradual cold shock

Gambar 3. Laju produksi $\mathrm{NH}_{3}$ lobster air tawar pada suhu $12^{\circ} \mathrm{C}$ selama 60 menit. Figure 3. $\mathrm{NH}_{3}$ production rates of freshwater lobster at $12^{\circ} \mathrm{C}$ within 60 minutes.

amonia cenderung mengalami penurunan hingga menit ke-45 seiring dengan berkurangnya aktivitas lobster menjadi lebih tenang. Namun setelah menit ke-45 laju produksi amonia kembali meningkat seiring dengan meningkatnya laju respirasi meskipun lobster mengalami disorientasi dan tidak tampak adanya aktivitas lagi. Dengan demikian, waktu shock selama 45 menit dengan menggunakan metode shock secara langsung berpeluang untuk digunakan pada penanganan dan transportasi sistem kering. Amonia merupakan senyawa yang bersifat toksik sehingga dibutuhkan kondisi produksi amonia yang serendah mungkin selama transportasi agar lobster tetap memiliki sintasan hidup yang tinggi ketika tiba di tempat tujuan.

Pada shock secara bertahap peningkatan produksi amonia di awal shock tampak lebih rendah bila dibandingkan dengan shock langsung. Hal ini disebabkan karena aktivitas lobster yang di-shock secara bertahap menunjukkan gerakan yang lebih tenang bila dibandingkan dengan shock langsung. Waktu shock selama 30 menit mampu menurunkan produksi amonia dari $0,92 \mathrm{ppm} / \mathrm{kg}$ ikan/jam hingga menjadi $0,76 \mathrm{ppm} / \mathrm{kg}$ ikan/jam. Setelah itu produksi amonia kembali meningkat hingga mencapai puncaknya pada menit ke-45. Dengan demikian waktu shock selama 30 menit dengan menggunakan metode shock secara bertahap berpeluang untuk digunakan pada penanganan dan transportasi lobster air tawar hidup sistem kering. Waktu shock hingga 60 menit kurang efektif meskipun menunjukkan penurunan produksi amonia karena membutuhkan waktu yang relatif lebih lama.

\section{Produksi Nitrit $\left(\mathrm{NO}_{2}\right)$}

Nitrit merupakan senyawa hasil reduksi senyawa nitrat $\left(\mathrm{NO}_{3}\right)$ dan atau oksidasi amonia $\left(\mathrm{NH}_{3}\right)$ oleh mikroorganisme yang bersifat toksik. Pembentukan nitrit dalam air dipengaruhi oleh kandungan oksigen bebas di dalamnya. Penguraian senyawa organik oleh mikroorganisme ini membutuhkan oksigen dalam jumlah banyak (Hutagalung et al., 1997).

Pola produksi nitrit selama shock disajikan pada Gambar 4. Laju poduksi nitrit pada shock secara langsung lebih rendah bila dibandingkan dengan laju produksi pada shock secara bertahap. Hal ini diperkirakan berkaitan dengan pasokan oksigen pada saat shock. Pada shock secara langsung, lobster mengalami fase panik sehingga konsumsi oksigen meningkat. Akibatnya pasokan oksigen terlarut dalam media air menurun sehingga penguraian senyawa organik hasil metabolit oleh mikroorganisme sangat sedikit. Sebaliknya, pada shock secara bertahap lobster cenderung lebih tenang sehingga tidak membutuhkan konsumsi oksigen yang banyak. Akibatnya pasokan oksigen terlarut dalam media air lebih banyak dan kemungkinan penguraian senyawa organik hasil metabolit oleh mikroorganisme lebih besar.

Pada shock secara langsung laju produksi nitrit berfluktuasi dan cenderung mengalami penurunan hingga 45 menit waktu shock, setelah itu kembali meningkat. Produksi nitrit terendah diperoleh pada menit ke-45, yaitu sebesar $0,036 \mathrm{ppm} / \mathrm{kg}$ ikan/jam. Sedangkan pada shock secara bertahap laju produksi nitrit terendah terjadi pada menit ke-30 yaitu 0,092 


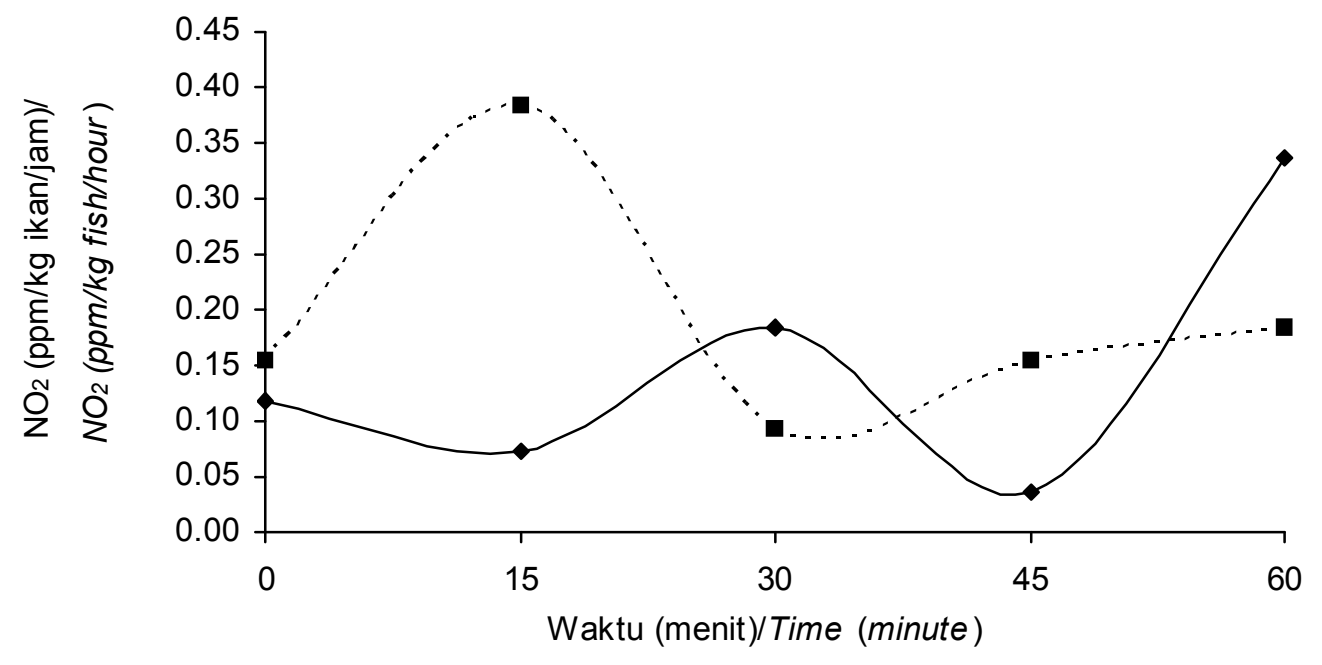

$\longrightarrow$ Shock langsung/Direct cold shock -..-... Shock bertahap/Gradual cold

Gambar 4. Laju produksi $\mathrm{NO}_{2}$ lobster air tawar pada suhu $12^{\circ} \mathrm{C}$ selama 60 menit.

Figure 4. $\mathrm{NO}_{2}$ production rates of freshwater lobster at $12^{\circ} \mathrm{C}$ within 60 minutes.

$\mathrm{ppm} / \mathrm{kg}$ ikan/jam, setelah itu kembali mengalami peningkatan. Hal ini berarti bahwa metode shock secara langsung selama 45 menit dan metode shock secara bertahap selama 30 menit berpeluang dalam penerapan penanganan dan transportasi lobster air tawar. Pada waktu tersebut produksi nitrit yang dihasilkan relatif rendah yang berarti pula produksi metabolit oleh lobster air tawar juga rendah, atau dengan kata lain lobster berada dalam metabolisme basal. Hal ini sangat diperlukan selama transportasi agar kelangsungan hidup lobster pada saat tiba di tempat tujuan tetap tinggi.

\section{KESIMPULAN}

1. Metode shock secara langsung menghasilkan fase panik terhadap lobster di awal shock namun setelah itu lobster menjadi lebih tenang dan akhirnya mengalami disorientasi. Pada metode shock secara bertahap menghasilkan pola aktivitas lobster yang hampir sama dengan metode shock secara langsung namun tanpa disertai fase panik di awal shock.

2. Metode shock secara langsung menunjukkan pola penurunan metabolisme hingga menit ke45 , setelah itu metabolisme kembali meningkat. Nilai terendah diperoleh pada menit ke-45 yang ditunjukkan dengan tingkat respirasi $81,2 \mathrm{ppm}$ $\mathrm{O}_{2} / \mathrm{kg}$ ikan/jam, produksi $\mathrm{NH}_{3}$ sebesar $1,29 \mathrm{ppm} /$ $\mathrm{kg}$ ikan/jam, dan $\mathrm{NO}_{2}$ sebesar $0,036 \mathrm{ppm} / \mathrm{kg}$ ikan/jam.

3. Metode shock bertahap menghasilkan pola metabolisme yang berfluktuasi. Tingkat metabolisme terendah diperoleh pada menit ke-30 dengan tingkat respirasi $58,5 \mathrm{ppm} \mathrm{O}_{2} / \mathrm{kg}$ ikan/jam, produksi $\mathrm{NH}_{3}$ sebesar $0,76 \mathrm{ppm} / \mathrm{kg}$ ikan/jam, dan $\mathrm{NO}_{2}$ sebesar 0,092 ppm/kg ikan/ jam.

4. Metode shock secara langsung selama 45 menit dan metode shock secara bertahap selama 30 menit berpeluang untuk digunakan dalam transportasi lobster air tawar hidup.

\section{SARAN}

Perlu dilakukan penelitian lebih lanjut mengenai uji aplikasi pada transportasi lobster air tawar hidup menggunakan metode shock secara langsung dan bertahap dengan waktu yang telah diperoleh untuk menentukan selang waktu dan metode yang paling efisien dan efektif yang dapat digunakan untuk penanganan dan transportasi lobster air tawar hidup.

\section{DAFTAR PUSTAKA}

Berka, R. 1986. The Transport of Live Fish : A Review. EIFAC Tech. Pap, FAO (48), Rome. p. 1-6.

Hutagalung, H.P., Deddy S., dan Hadi R. 1997. Metode Analisis Air Laut, Sedimen dan Biota. Buku 2. Pusat Penelitian dan Pengembangan Oseanologi, LIPI, Jakarta. $182 \mathrm{pp}$.

Jones, C.M. 1998. Redclaw Crayfish. The New Rural Industries: A Handbook for Farmers and Investors. Freshwater Fisheries and Aquaculture Centre. Department of Primary Industries Walkamin, Australia. $128 \mathrm{pp}$.

Lawrence, C.S., Morrissy, N.M., Penn, J., and Jacoby, K. 1995. Yabbies (Cherax albidus). Aquaculture WA. (4): 4. 
Lin, T.S., Liu, F.G., and Liao, I.C. 1994. Experiment on adaptation of Australian crayfish to selected environmental factors. Aquaculture. 122(1): 75-80.

Surono, Ismanadji I., Djazuli N., dan Sunarya. 1993. Pengujian transportasi hidup dengan metoda hibernasi. Prosiding Simposium Perikanan Indonesia I. Jakarta. p. 1-5.

Suryaningrum, T.D., Setiabudi, E., Muljanah, I., dan Anggawati, A.M. 1994. Kajian penggunaan metode pembiusan secara langsung pada suhu rendah dalam transportasi lobster hijau pasir (Panulirus humarus) dalam media kering. J. Pen. Pasca Panen Perikanan. 79: 56-72.

Suryaningrum, T.D., Wibowo, S., Muljanah, I., Peranginangin, R., Hastarini, E., Syamdidi, dan Ikasari, D. 2006. Riset penanganan dan transportasi ikan hidup air tawar. Laporan Teknis. Pusat Riset Pengolahan Produk dan Bioteknologi Kelautan dan Perikanan, Badan Riset Kelautan dan Perikanan, Jakarta. p. 1-15.

Syamdidi, Ikasari, D., dan Wibowo, S. 2006. Studi sifat fisiologi ikan gurami (Osphronemus gourami) pada suhu rendah untuk pengembangan teknologi transportasi ikan hidup. JPB Perikanan. 1(1): 7583.
Wibowo, S., Setiabudi, E., Suryaningrum, T.D., dan Sudrajat, Y. 1994a. Pengaruh penurunan suhu bertahap terhadap aktivitas lobster hijau pasir (Panulirus humarus). J. Pen. Pasca Panen Perikanan. Balai Penel. Perikanan Laut, Jakarta. 79: 24-36.

Wibowo, S., Suryaningrum, T.D., Suherman, M., dan Suparno. 1994b. Studi penggunaan metoda penurunan suhu bertahap dalam transportasi sistem kering untuk lobster hijau pasir (Panulirus humarus). J. Pen. Pasca Panen Perikanan. Balai Penel. Perikanan Laut, Jakarta. 79: 37-55.

Wibowo, S., Suryaningrum, T.D., dan Utomo, B.S.B. 2002. Kajian sifat fisiologis kerapu lumpur (Epinephelus tauvina) sebagai dasar dalam pengembangan teknik transportasi hidup. J. Penel. Perik. Indonesia Edisi Pasca Panen. 8(6): 1-9.

Wibowo, S., Suryaningrum, T.D., Muljanah, I., Peranginangin, R., Hastarini, E., Syamdidi, dan Ikasari, D. 2005. Riset penanganan dan transportasi ikan hidup air tawar. Laporan Teknis. Pusat Riset Pengolahan Produk dan Bioteknologi Kelautan dan Perikanan, Badan Riset Kelautan dan Perikanan, Jakarta. p. 48-57.

Winarno, F.G. 2003. Transportasi Hidup Ikan dan Domba. M-brio Press, Bogor. 49 pp. 
